\title{
Passive and Active Acoustics Using an Autonomous Wave Glider
}

\section{Brian Bingham and Nicholas Kraus}

Department of Mechanical Engineering, University of Hawaii at Manoa, Honolulu, Hawaii 96822

e-mail: bsb@hawaii.edu,nkraus@hawaii.edu

\section{Bruce Howe}

Department of Ocean and Resources Engineering, University of Hawaii at Manoa, Honolulu, Hawaii 96822

e-mail: bhowe@hawaii.edu

Lee Freitag, Keenan Ball, Peter Koski, and Eric Gallimore

Department of Applied Ocean, Physics and Engineering, Woods Hole Oceanographic Institution, Woods Hole, Massachusetts 02543

e-mail:Ifreitag@whoi.edu,kball@whoi.edu,pkoski@whoi.edu,egallimore@whoi.edu

Received 9 September 2011; accepted 22 February 2012

\begin{abstract}
The recently developed wave glider has the potential to be an effective unmanned platform for acoustic applications. We present the results of a variety of experiments that quantify this potential. The radiated selfnoise of the autonomous platform is evaluated using an integrated passive acoustic recorder during a set of field trials off the coast of Hawaii. We present the radiated noise spectra from these trials to illustrate the dependence on hydrophone location and sea state. Using the same instrumentation, we demonstrate the ability of a modified wave glider to detect marine mammals using passive acoustic monitoring techniques. We also evaluate the performance of the wave glider operating as an active acoustic gateway, highlighting the potential of this platform to serve as a navigation reference and communications relay for scientific, industrial, and military subsea assets. To demonstrate the potential of the wave glider platform to support acoustic navigation, we assess the performance of time-of-flight range estimation and seafloor transponder localization. These tests were performed using commercial off-the-shelf acoustic positioning hardware integrated with the wave glider to illustrate that the low self-noise of the wave glider makes it possible to achieve acoustic positioning performance similar to previously reported results. Finally, we show that the glider can operate as a station-keeping surface communications gateway and provide recommendations for its use. (ㅇ 2012 Wiley Periodicals, Inc.
\end{abstract}

\section{INTRODUCTION}

Exploring, understanding, and monitoring the marine environment are fundamentally limited by our ability to transmit signals through the ocean acoustic channel. The ocean is essentially opaque to electromagnetic waves, but sound waves can travel long distances with relatively low attenuation. For this reason, acoustic instruments are a fundamental component in many marine operations.

Robotic vehicles serve in an increasing variety of roles for scientific, industrial, and military endeavors. Many of these platforms, such as remotely operated vehicles (ROVs) and autonomous underwater vehicles (AUVs) (or unmanned underwater vehicles (UUVs)), have reached a sufficiently high level of maturity to be considered commercial off-the-shelf assets. Recently a new type of vehicle has emerged. Developed by Liquid Robotics, Inc. (LRI), the

Direct correspondence to: Brian Bingham, e-mail: bsb@hawaii.edu. wave glider is a wave-propelled unmanned surface vessel (USV) that is capable of long-duration deployments of a year or more.

Many of the potential applications for this novel platform involve passive and active acoustics. For example, passive monitoring has been shown to be an effective tool for understanding marine mammals and monitoring ship traffic (as well as a variety of military applications). Currently these passive systems are often moored near the seafloor or towed by surface ships. As a platform for passive monitoring the wave glider provides distinct advantages; it is mobile, provides ample solar power for persistent deployments, emits very little acoustic energy to interfere with incoming sound, provides real-time access to collected observations, and operates autonomously, eliminating the expense of a surface ship.

Active acoustics also plays an important role in marine operations, especially navigation and communication. A pervasive limitation of acoustic navigation has been the 
need for fixed transponders on the seafloor. The wave glider has the potential to provide a more flexible, mobile solution without the need for a dedicated surface ship. For example, a wave glider, augmented with acoustic navigation and communication instruments, could serve as a navigation gateway for one or multiple AUVs (either powered vehicles or underwater gliders). A set of wave gliders could provide the same functionality as GPS satellite vehicles, providing absolute position updates (albeit spatially limited by acoustic propagation).

This article describes the application of this new class of USV to support active and passive acoustic functions. Because of the relatively recent emergence of this tool, many of its capabilities (and limitations) are still in question. We describe the results of experiments and analysis to quantify the performance of this new platform for acoustic applications. The goals of this work are as follows:

- Quantify the acoustic signature of the wave glider

- Evaluate the performance of the wave glider as a platform for passive acoustic monitoring

- Demonstrate active acoustic ranging and evaluate the potential of the wave glider as an acoustic navigation gateway to support underwater localization

- Test the ability of a modified wave glider to precisely localize seafloor instrumentation

- Demonstrate acoustic communication between the glider and seafloor instrumentation

\section{BACKGROUND AND CLOSELY RELATED WORK}

\subsection{The Wave Glider}

The wave glider is a new class of wave-propelled, persistent, unmanned ocean vehicle. The key innovation of the wave glider is its ability to harvest the abundant energy in ocean waves to provide essentially limitless propulsion (Hine, Willcox, Hine, \& Richardson, 2009). As illustrated in Figure 1, the wave glider is composed of a submerged glider attached via an umbilical to a surface float and is propelled by the conversion of ocean wave energy (differential vertical motion) into forward thrust, independent of wave direction. In this article we refer to the two-body system in the following way: the surface body is the float; the submerged body is the glider; and the complete vehicle is the wave glider. Except for the energy required to quasi-statically adjust rudder position, the wave energy propulsion system is purely mechanical. Using this propulsion system, the wave glider can maintain a typical forward speed of $0.75 \mathrm{~m} / \mathrm{s}$ (1.5 kts) in seas as small as $0.5-1.0 \mathrm{~m}$ wave height (Willcox et al., 2009).

\subsection{Passive Acoustic Monitoring}

One anticipated application of the wave glider platform is passive acoustic monitoring of marine mammals. Traditionally, visual surveys have been used to monitor marine

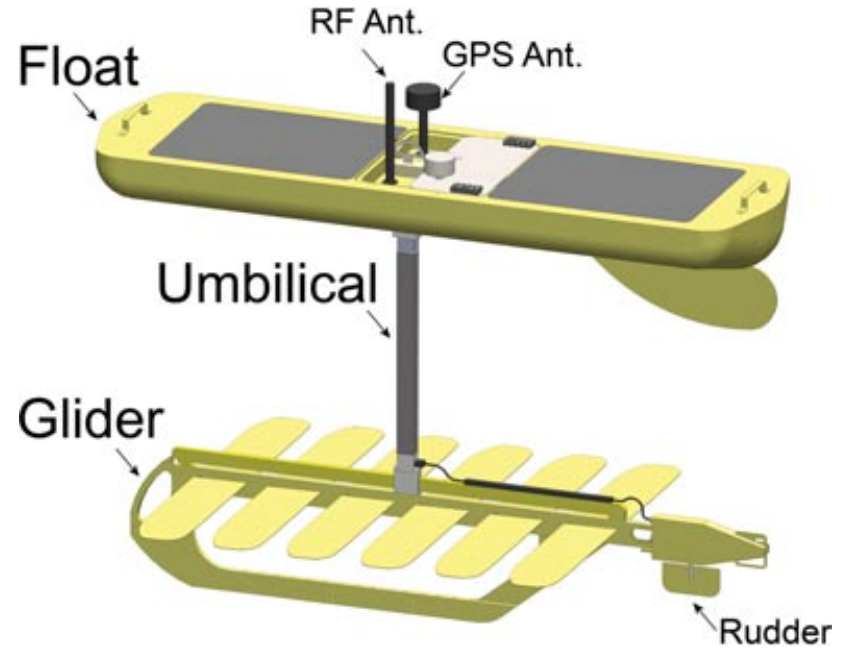

Figure 1. Model of the Liquid Robotics, Inc. wave glider with annotations to highlight the major subsystems. The forward and aft solar panels are shown on top of the float; the payload instrument housings are located underneath each solar panel.

mammal behavior. These surveys are limited because observers can only see animals during the short time they are at the surface and these surveys can only be conducted during daylight hours in relatively good weather (Mellinger, Stafford, Moore, Dziak, \& Matsumoto, 2007). Because of these shortcomings, passive acoustic monitoring-using hydrophones at fixed locations or on moving platformshas become a standard method for detecting, classifying, and localizing marine mammals. Stationary hydrophones enable continuous sampling for complete temporal coverage, but with limited spatial coverage. In contrast, shiptowed hydrophones can achieve large spatial coverage, but the monitoring duration (temporal coverage) is limited by the high operational cost of research vessels and surface ships (Mellinger \& Barlow, 2003).

More recently, the community has realized the potential for robotic platforms to provide a mobile, persistent, low-cost monitoring capability to achieve both temporal and spatial coverage. Underwater gliders have been the focus of much of this work. Acoustic recorders integrated into the Seaglider (iRobot Corporation) were deployed in 2006 to monitor a variety of cetacean species in Monterey Bay, California (Moore, Howe, Stafford, \& Boyd, 2008). During other deployments, the same system recorded transmissions from the 75- $\mathrm{Hz}$ Kauai acoustic thermometry of ocean climate (ATOC) source located off Kauai, as well as naval sonars (Howe \& Boyd, 2008). Similarly, a set of Slocum gliders (Teledyne Webb Research) was deployed in the Gulf of Maine to study the feeding behavior of sei whales (Baumgartner \& Fratantoni, 2008).

Unmanned surface vessels are likely to be the next platform for autonomous monitoring. The high-frequency 
acoustic recording package (HARP) system (Wiggins \& Hildebrand, 2007) has been demonstrated aboard a wave glider for passive monitoring (Wiggins, Manley, Brager, \& Woolhiser, 2010). Our experimental results expand on this earlier report by providing sound-pressure-level estimates for a broader frequency range than previously reported. We also present an evaluation of the capabilities of the wave glider platform for active acoustic functions: navigation and communication. Researchers have also proposed an autonomous sailboat for passive acoustic monitoring to address the speed and payload limitations of underwater glider based solutions (Klinck, Stelzer, Jafarmadar, \& Mellinger, 2009).

\subsection{Active Acoustic Navigation}

Underwater navigation has been a topic of research and development for more than four decades as military, industrial, and scientific applications have created the need for methods to precisely position underwater assets. This impetus has led to a wide array of commercial off-the-shelf instrumentation options as well as a variety of methods for combining these sensors into a complete navigation solution (see Kinsey, Eustice, \& Whitcomb, 2006; Leonard, Bennett, Smith, \& Feder, 1998; Stutters, Liu, Tiltman, \& Brown, 2008) for review articles).

In long-baseline (LBL) acoustic positioning, a standard in underwater navigation, location is estimated via multilateration using distances measured acoustically from fixed transponders. First used in the 1960s and 1970s (Hunt et al., 1974), acoustic transponders moored to the seafloor have been used to estimate the positions of a wide spectrum of underwater assets: submersibles, towed instrumentation, ROVs, and AUVs (Milne, 1983). The typical operation of an LBL system (described in Whitcomb, Yoerger, Singh, \& Mindell, 1998; Yoerger, Jakuba, Bradley, \& Bingham, 2007) includes transponder deployment, sound-velocity profile measurement, transponder survey prior to subsea operation, and transponder recovery after the operation completion.

Many research efforts in underwater navigation seek to reduce (or remove) the role of seafloor-moored transponders in a navigation solution or to eliminate the need to survey the deployed transponders from the surface-a process that consumes considerable operational time. One solution is to place the transponders at the surface on floating buoys so that constant position updates can be acquired via GPS. This approach has been used for tracking. AUVs for survey operations (Austin, Stokey, \& Sharp, 2000; Desset, Damus, Morash, \& Bechaz, 2003) and for tracking of submerged acoustic arrays (Howe, Mercer, \& Spindel, 1989). It is important to distinguish tracking (determining the location of the mobile asset remotely in real time or through post-processing) from positioning (determining the location in real time aboard the mobile asset for navigation). The advantage of using a wave glider for this scenario, rather than drifting buoys, is that the wave glider is mobile, allowing it to maintain position over the operational area or to coordinate its motion with the requirements of the subsea assets.

Using reliable acoustic communication to support navigation has generated new solutions, which continue to reduce the dependence on acoustic transponders. With the ability to transmit ephemeris data from a surface ship to the submerged platform, it becomes possible to eliminate the transponders altogether and use the moving surface ship (with GPS navigation) as an absolute reference (Webster, Eustice, Singh, \& Whitcomb, 2009; Eustice, Whitcomb, Singh, \& Grund, 2007). A similar solution used powered autonomous surface vehicles to provide a moving baseline for subsea navigation (Curcio et al., 2005; Vaganay, Leonard, Curcio, \& Willcox, 2004). The Hugin AUV, a successful commercial survey tool, has used acoustic communication to provide position updates and change the AUV mission from the surface (Vestgard, Storkersen, \& Sortland, 1999). The advantage of using a wave glider to provide this functionality is that it eliminates the need for a surface ship, reducing the personnel and energy costs through the use of a small, autonomous robot that can be deployed for long-duration missions.

\subsection{GPS/Acoustic Positioning of Subsea Instruments}

Determining the absolute georeference position of instruments fixed to the seafloor is an important capability for applications such as LBL positioning and seafloor geodesy. For both these applications, the position of moored transponders is estimated by maneuvering the ship around each transponder while repeatedly measuring the time of flight of acoustic signals between the transponder and the ship-mounted transducer. This empirical measurement of the slant range is then compared with a prediction of the slant range, which is a function of the measured shipmounted transducer position and the unknown transponder position. The transponder position can be estimated by minimizing the error between the acoustically measured slant ranges and the predicted slant ranges.

As discussed earlier, the transponder survey is an important preliminary step in LBL navigation; the accuracy of the navigation solution can only be as good as the georeferenced locations of the transponders. Using off-the-shelf acoustic positioning transponders and the surface ship's GPS position (typically P-code based) and heading, it is possible to determine the position of each transponder to within "just a few meters" (Whitcomb, et al., 1998). In a previous work we found that the root-mean-squared residual resulting from surveying three transponders for use with an AUV ranged from 1.5 to $2.1 \mathrm{~m}$ using transponders (Teledyne Benthos, TR-6001) at $7-15 \mathrm{kHz}$ with a $10-\mathrm{ms}$ pulse length (Bingham et al., 2010).

Precise positions of seafloor-mounted transponders can also be used to detect seafloor crustal movement in 
seismically active locations. This method was originally implemented by Spiess et al. (Spiess et al., 1998) using custom high-precision transponders with a timing resolution of $10 \mu \mathrm{s}$ (Spiess, Boegeman, Zimmerman, Chadwell, \& Hildebrand). The resulting experiment demonstrated horizontal positioning repeatability (precision) of less than $5 \mathrm{~cm}$, where the center of a transponder array was estimated to infer crustal motion. Other studies have used similar methods combining high-precision ship-based GPS and acoustic range estimation to position transponders in arrays or as single units (Fujita et al., 2006; Obana, Katao, \& Ando, 2000; Osada et al., 2003; Sweeney, Chadwell, Hildebrand, \& Spiess, 2005; Yamada et al., 2002). The experimental results illustrate that the position of the seafloor instruments can be estimated with a repeatability of better than $20 \mathrm{~cm}$, with some reported precision values of better than $5 \mathrm{~cm}$. Furthermore, these high-precision techniques have been applied to AUV navigation to achieve an absolute accuracy of $\pm 30 \mathrm{~cm}$ (Kussat \& Chadwell, 2005). The limiting factor in determining seafloor position with this level of resolution is the lack of observability of the instantaneous sound velocity profile (Yamada et al., 2002). The results presented in this article show that the wave glider has the potential to support positioning of subsea instruments, replacing (or augmenting) a dedicated surface ship to accomplish the acoustic interrogation.

\subsection{Supporting Acoustic Communication}

Employing a wave glider as an acoustic communications gateway for either fixed or mobile undersea systems is also an attractive use of the energy-harvesting platform. The most obvious application of the wave glider gateway is to substitute for fixed wireless buoys that link subsea acoustic data with satellite telemetry. Examples include deepocean assessment and reporting of tsunamis (DART) buoys (Lawson et al., 2011; Meinig, Stalin, Nakamura, \& Milburn, 2005) and buoy-based deep-water ocean observatories (Frye et al., 2005). Deep-ocean buoys are very expensive and must be maintained regularly, whereas subsea instruments, once in place and equipped with sufficient power, can operate for several years. The station-keeping capability of the wave glider in most areas of the world (though not all) is sufficient to keep it easily within $1 \mathrm{~km}$ of a desired point on the ocean surface, meaning that coverage will be continuous.

Use of the glider as a gateway for monitoring deep mobile systems is also possible, though the speed of the glider is less than that of most powered vehicles. However, for certain types of surveys, in particular where a deep vehicle is driving on closely spaced track lines in a relatively small area, the wave glider can easily provide a link to shore or a nearby ship via the acoustic modem and radio or satellite link.

\section{EXPERIMENTAL SETUP}

Two wave gliders were involved in these experiments. One was acquired and modified by the University of Hawaii at Manoa (UHM), the other by the Woods Hole Oceanographic Insitution (WHOI). The UHM wave glider was configured primarily for passive characterization and active navigation. The WHOI wave glider was configured for acoustic communication. Figure 2 shows the locations of

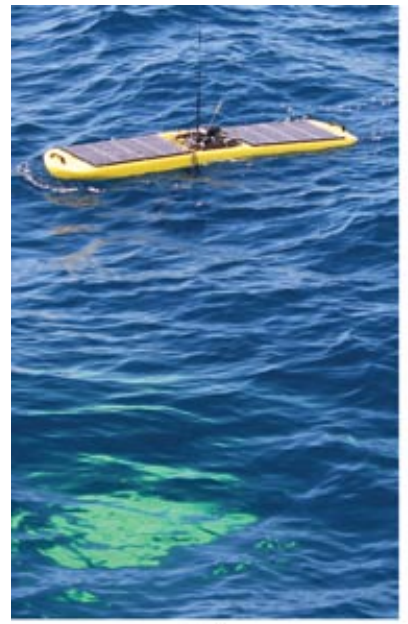

(a)

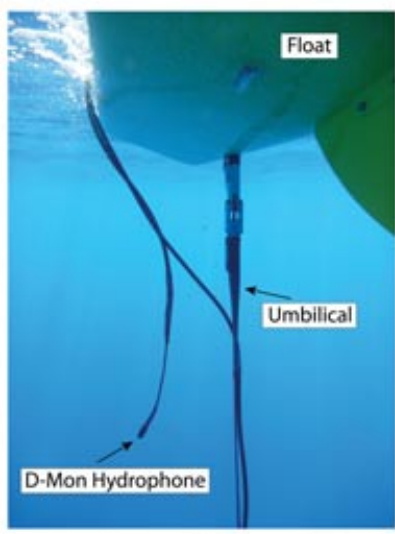

(b)

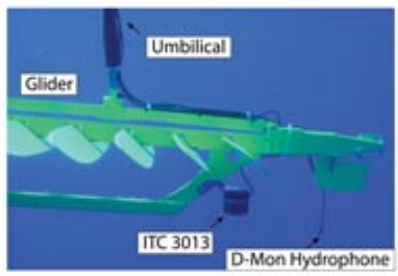

(c)

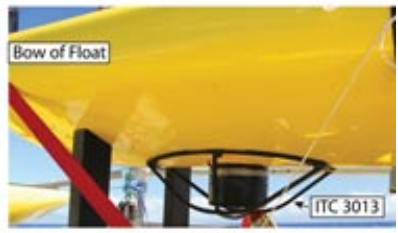

(d)

Figure 2. Images of the acoustic hardware integration aboard the UHM and WHOI wave gliders. (a) Top view of the operational UHM wave glider. (b) Image showing the upper D-MON hydrophone near the UHM wave glider surface float. (c) Image showing both the ITC-3013 transducer and the D-MON hydrophone mounted on the stern of the UHM submerged glider. (d) Image showing the ITC-3013 micro-modem transducer mounted in the float of the WHOI wave glider. An acoustically transparent faired flow shield (not shown) covers the cage to reduce drag. 
the passive and active acoustic transducers aboard the two wave gliders.

\subsection{The UHM Wave Glider}

The UHM wave glider was augmented with a passive acoustic recorder, an acoustic modem (for navigation and communication), and navigation aids to improve the positioning of the vehicle. The D-MON passive recording system was included to quantify the acoustic environment near the wave glider and to evaluate the potential of the wave glider for passive marine mammal monitoring. The D-MON was developed at WHOI to be capable of both high-fidelity passive acoustic monitoring and flexible implementation of embedded real-time detection algorithms. Two D-MON hydrophones were added to the wave glider-one directly below the surface float and one at the stern of the subsurface glider (see Figures 2(b) and 2(c)).

A WHOI micro-modem (Freitag et al., 2005) was integrated into the UHM wave glider to support both acoustic navigation and communication. An ITC-3013 acoustic transducer was used with the micro-modem. Based on the results of the early D-MON recordings (described in Section 4), the transducer was mounted on the subsea glider as shown in Figure 2(c) to reduce the ambient noise.

It was also necessary to integrate navigation, telemetry, and data-logging hardware to support the experimental evaluation of passive and active acoustic performance of the wave glider. We integrated a GPS receiver (Trimble ProXT and external antenna with sub-meter real-time accuracy) to improve the performance of the standard receiver from LRI. We also integrated an inertial measurement unit (IMU) (Microstrain 3DM-GX2) to augment the GPS position and to directly measure the ocean conditions at the wave glider. A line-of-sight wireless telemetry system(Freewave MM2-P-T Ethernet radio) was included to provide a high-bandwidth connection between the wave glider and the base station located aboard the R/V Klaus Wyrtki. The onboard instrumentation data were archived aboard the wave glider using an embedded single-board computer.

The instruments were powered by a combination of the wave glider's solar panels (during the day) and onboard battery storage (during the night). The total power consumption for all the added instrumentation was $26 \mathrm{~W}$. This total is dominated by the onboard processor included for the test $(18 \mathrm{~W})$. The wave glider included $665 \mathrm{Wh}$ of battery capacity and two 43-Wh solar panels. The actual available power supplied by the panels depends greatly on the local solar conditions. During our deployments the solar panels were able to fully change the batteries during daylight hours despite the additional power draw. Future long-duration deployments would require a more powerefficient processing solution, but, for the purposes of our experimental assessment, having a fully functional computing environment on board was advantageous.

\subsection{The WHOI Wave Glider}

On the WHOI wave glider the ITC-3013 transducer for acoustic communications was mounted on the underside of the surface float. Integration of external sensors on the wave glider, including acoustic transducers or hydrophones, is challenging because of the need to minimize drag. LRI has taken a significant amount of care to reduce the drag of all components of the glider, and previous work had shown that, for example, large cables added to the umbilical greatly reduced the ability of the wave glider to propel itself through the ocean. Thus an important part of the design work was developing components that would add as little drag as possible.

As mentioned earlier, the WHOI wave glider is configured as a station-keeping acoustic communications gateway buoy. Using information from a previous modem integration with the wave glider (LRI internal report), where the transducer was embedded in the float to eliminate signal reflections from the surface that were reducing reliability, the same approach was followed for the initial integration on the WHOI wave glider, as shown in Figure 2(d). However, platform-generated noise was not measured in the previous LRI work, and it was suspected that although eliminating surface reflections was important, the noise field near the float could also impact performance. Thus a broadband recorder was added to monitor the input to the acoustic modem for platform noise effects. During the tests described in later sections, the modem and the recorder were operated in parallel.

\section{RESULTS OF PASSIVE ACOUSTIC OBSERVATIONS}

Quantifying the acoustic signature of the wave glider is an important aspect of evaluating the potential of the platform to support acoustic applications. Our hypothesis is that because the vehicle has only one actively moving part (the rudder) and passively moving wings, it will be an ideal platform for deploying sensitive passive monitoring instrumentation.

The UHM wave glider, with the D-MON passive acoustic recorder, was operated for six days between February 24 and March 15, 2011 off the south coast of Oahu. The D-MON recorded two channels continuously during operations-one for the hydrophone below the float and one for the hydrophone located on the glider. As much as possible, the research vessel used for deployment and recovery was separated from the wave glider with the engine and generators turned off. The sea state during the trials was generally calm, with larger swells on the last day of operations (March 15). The wind and sea conditions during the pertinent operational days are described in Table I. These observations are from NOAA's on-shore weather station (OOUH1) and the nearby NOAA data buoy (Station 51204). 
Table I. Environmental conditions during operational days.

\begin{tabular}{lccc}
\hline $\begin{array}{l}\text { Date } \\
(2011)\end{array}$ & $\begin{array}{c}\text { Avg. wind } \\
\text { speed (m/s) }\end{array}$ & $\begin{array}{c}\text { Max. wind } \\
\text { gusts (m/s) }\end{array}$ & $\begin{array}{c}\text { Sig. wave } \\
\text { height (m) }\end{array}$ \\
\hline Feb. 24 & 2.3 & 3.8 & 1.0 \\
March 10 & 4.0 & 7.5 & 1.5 \\
March 15 & 3.2 & 5.1 & 2.8 \\
\hline
\end{tabular}

The relatively calm ocean conditions allowed a careful characterization of the wave glider noise. However, the trials were conducted between 6-35 km from Honolulu Harbor, so a significant amount of surface vessel traffic was plainly evident in much of the passive record. In addition, cetacean vocalizations were ubiquitous during the trials.

\subsection{Wave Glider Acoustic Signature}

To characterize the acoustic signature of the wave glider, we present a brief analysis of the three days of passive D-MON recordings made at using the two hydrophones fixed to the surface float and submerged glider (see Figures 2(b) and 2(c)). Figures 3 and 4 illustrate the acoustic signature of the wave glider and highlight the observed differences between the two locations. The power spectral density (PSD) estimates and spectrograms were generated using a sample rate of $120 \mathrm{kHz}$, a 4,096-point Fast Fourier

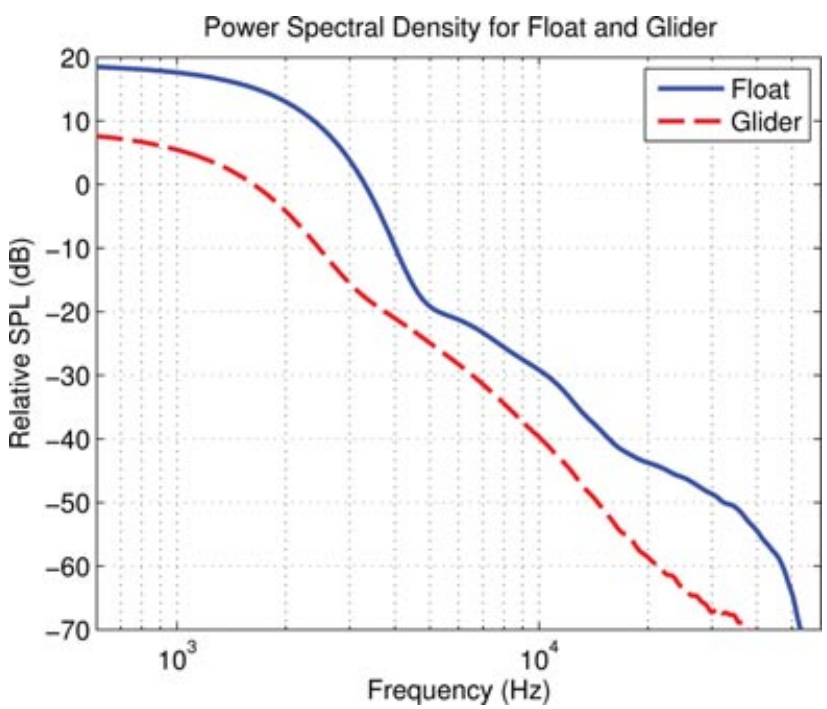

Figure 3. Power spectral density estimates for the ambient noise recorded on the D-MON hydrophones. The two curves illustrate the difference between the noise at the two hydrophone locations, directly below the float and at the stern of the glider, as shown in Figure 2.

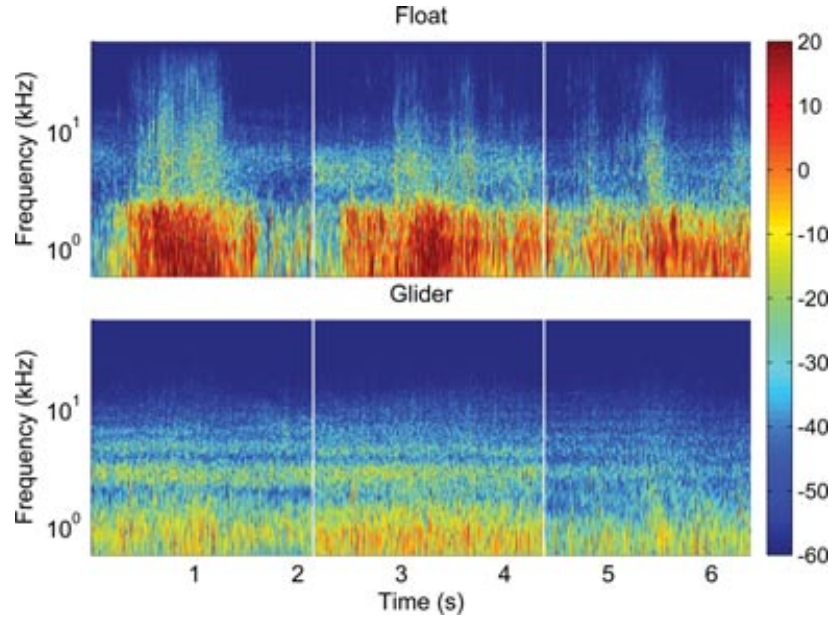

Figure 4. Composite spectrogram for three selections from passive recordings on the wave glider. The upper axes show the spectrogram for the hydrophone located directly below the float and the lower axes show the spectrogram from the same time period as received at the glider. Frequencies from 600 to $60,000 \mathrm{~Hz}$ are shown. The units on the color bar are relative sound pressure levels in decibels. The two vertical lines appear because three separate selections were combined to generate an overview of the noise events.

Transform (FFT), a Blackman-Harris window, and 50\% overlap. The PSD estimates and spectrograms in Figures 3 and 4 are generated from the same recording. The PSD in Figure 3 shows that the overall noise level at the float is roughly $10 \mathrm{~dB}$ higher than that at the glider. The spectrogram in Figure 4 illustrates one cause of this added noise: the spectrogram shows intermittent broadband bubble noise generated by the surface float. The bubble noise does reach the hydrophone at the glider, but, based on our experimental analysis, is greatly diminished at $7.5 \mathrm{~m}$ depth.

Figure 5 provides greater detail concerning this general observation. The PSD estimates are shown for each of three operational days when there was a substantial difference in the significant wave height. Furthermore, the wave glider signatures are compared with the Ambient noise spectrum collected by deploying the D-MON independent of the wave glider with the hydrophones at approximately the same depths. This background noise level is shown in Figure 5 (dashed line). The ambient noise quantification was only performed once (on February 24) because of operational constraints. All the spectra illustrate the extremely low self-noise generated by the configuration. The $20-\mathrm{kHz}$ peak in the glider spectrum for March 15 (the blue curve in the lower panel of Figure 5) is due to an unidentified external noise source in the area. We do not know the source of this signal, but it was persistentlasting the entire operation-and was not generated by our 


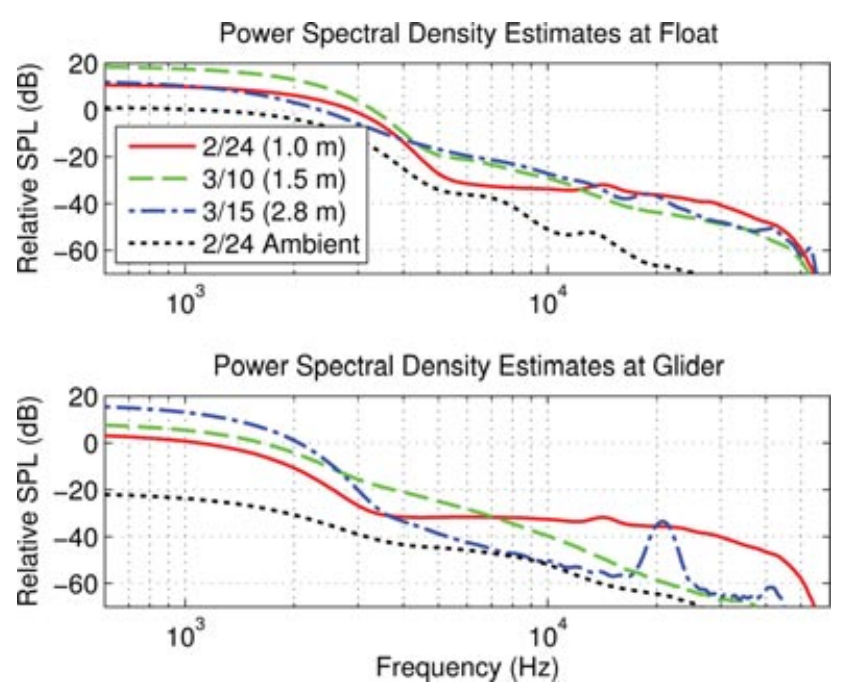

Figure 5. Power spectral density estimates from two hydrophones: one directly below the float (Figure 2(b)) and one at the stern of the glider (Figure 2(c)). Each estimate is for a particular day of operation. The reported significant wave height (as a surrogate for sea state) is indicated in the legend. The $20-\mathrm{kHz}$ peak in the glider spectrum for March 15 is due to an unidentified external noise source in the area.

operation. The testing area off the south shore of Oahu is near an active harbor and Navy base, either of which could have been the source of this narrowband signal.

Figures 3-5 are included to illustrate the following conclusions:

- Overall the noise generated by the wave glider is very low, indicating the platform's aptitude as an active and passive acoustic platform.

- The ambient noise at the submerged glider is significantly lower than the ambient noise at the surface float (Figure 3).

- The sea state does not have a strong influence on the vehicle's emitted noise (Figure 5).

Based on these results, we conclude that there is a substantial benefit to locating any acoustic transducers on the submerged glider, rather than on the surface float.

\subsection{Passive Acoustic Monitoring}

Because of the low self-noise quantified earlier, we were able to passively detect many marine mammals and surface ships in the area. As a proof of concept, Figure 6 shows one example of humpback whale vocalizations recorded during the deployment.

To quantify the quality of the wave glider recordings, we compare the SNR of the recording shown in Figure 6 with a standard data set. For both records the SNR is calculated using the method described by Mellinger and Clark

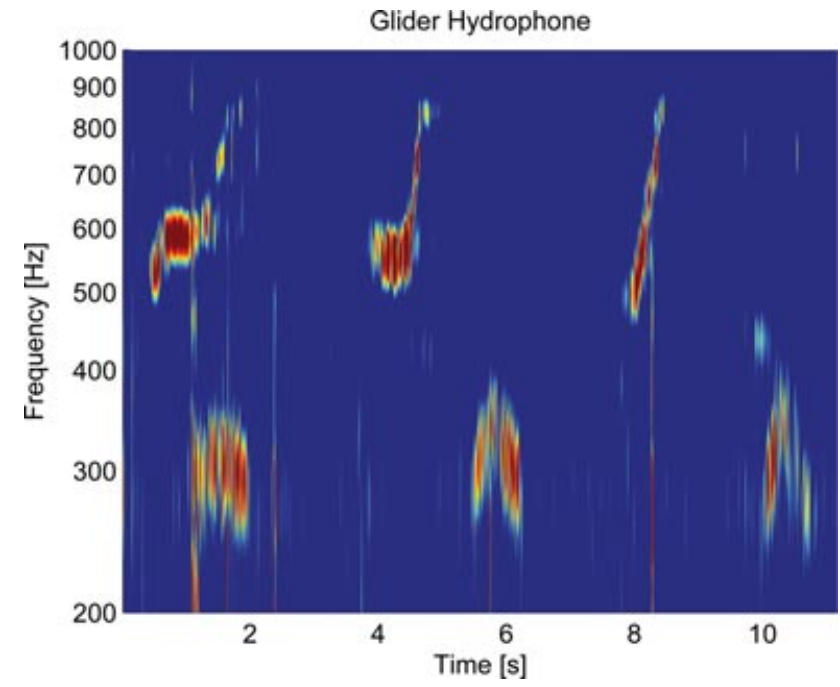

Figure 6. Example of humpback whale (Megaptera novaeangliae) vocalization recorded using the D-MON system mounted on the UHM wave glider. The vocalizations shown are centered around roughly $600 \mathrm{~Hz}$ and $300 \mathrm{~Hz}$. Spectrogram parameters: sampling rate $120 \mathrm{kHz}$, FFT size 4,096 samples, $90 \%$ overlap, Blackman-Harris window.

(2006). For the wave glider example this SNR was estimated to be $15.0 \mathrm{~dB}$. This can be compared to archived recordings of humpback vocalizations made off the north coast of Kauai, Hawaii in March 1994 using a custom sonobuoy hydrophone array (Frankel, Clark, Herman, \& Gabriele, $1995)^{1}$. For this standard data set the observed SNR was $27.9 \mathrm{~dB}$ with a standard deviation of $14.8 \mathrm{~dB}$. Although the SNR for the wave glider/D-MON based recording is less than the mean SNR of the Kauai data, it is within one standard deviation of the Kauai data, suggesting that the performance of this system is comparable to the moored hydrophone recordings.

\section{RESULTS OF ACTIVE ACOUSTIC EXPERIMENTS: NAVIGATION}

To demonstrate the capabilities of the wave glider as an acoustic navigation gateway, we deployed acoustic transponders (Teledyne Benthos, TR-6001) in two locations. At the first location, the wave glider performed a localization survey of a transponder deployed at a depth of approximately $250 \mathrm{~m}$. At the second location, we attempted to determine the maximum distance of two-way ranging with the transponder deployed at a depth of approximately $500 \mathrm{~m}$.

${ }^{1}$ Acoustic data and annotations are available from the MobySound database-http://www.mobysound.org/ (Mellinger \& Clark, 2006). 


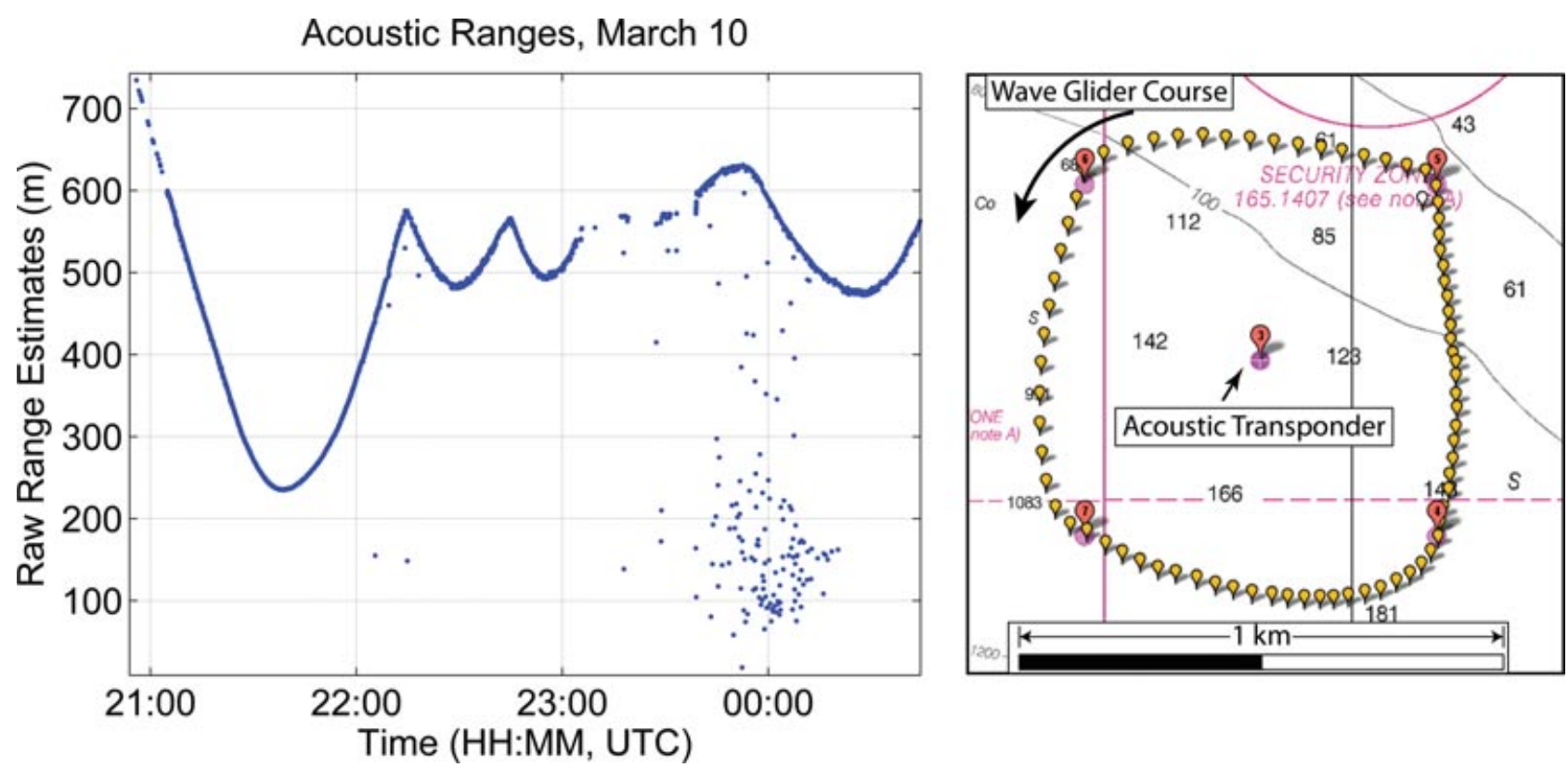

Figure 7. Results from acoustic transponder survey using the UHM wave glider. (a) Unfiltered (raw) acoustic range measurements from transponder survey. Range estimates are produced from the reported one-way travel times and the approximate speed of sound in the area during operation. The early returns evident around 00:00 UTC were the result of simultaneous acoustic communication tests in the same area, which caused false detections. (b) Map showing the survey path of the wave glider. Waypoint 3 (center) is the deployment location of the transponder. The other waypoints are goals for the glider control. The yellow markers show the GPS updates from the wave glider's iridium telemetry. The chart underlay is from the NOAA navigational chart showing soundings in fathoms. The axes are in latitude and longitude. (Image courtesy of Liquid Robotics, Inc.).

\subsection{Acoustic Range Estimation}

Figures 7 and 8 illustrate two experimental evaluations of active slant range measurement from the UHM wave glider. The figures present the range estimates based on the raw travel times to emphasize the high reliability of the receptions. Figure 7(a) shows a group of early returns around 00:00 UTC. These were caused by simultaneously doing acoustic communication tests in the same area. These tests were in the same frequency band and caused the transponder to reply before interrogation, resulting in early detections.

The returns in Figure 8(a) illustrate the results of a trial attempting to determine the maximum possible distance for range estimation. Despite the glider being piloted over $3 \mathrm{~km}$ away from the transponder, the ranges were consistent throughout the trial. Figure 9 shows the signal-tonoise ratio (SNR) of the received acoustic responses from the transponder as a function of the distance from the transponder. To estimate the maximum possible range, we fitted a line to the log-log plot of SNR versus range by minimizing the least squared error. The slope of the line shows a transmission loss of $-16.0 \mathrm{~dB} /$ decade, which is consistent with spreading and seawater attenuation. Extrapolating this trend, we could expect to receive a signal of this strength at distances of up to $40 \mathrm{~km}$, based on the noise floor shown in Figure 9. This coarse approximation ignores the ray bending, which would limit the horizontal propagation, but the results do illustrate that the performance of the system as integrated on the wave glider is limited by the acoustic propagation and not by the vehicle configuration. We expect that open ocean ranges up to $10 \mathrm{~km}$ (as normally observed in practice) should be achievable with the wave glider as configured here.

\subsection{Localization Survey}

An important operational step for underwater acoustic positioning is accurately determining the location of the fixed transponders with known accuracy. The uncertainty in the transponder locations contributes directly to the overall uncertainty of the positioning solution. Using the system described earlier, we executed a proof-of-concept survey of a seafloor transponder by circumnavigating the transponder while simultaneously interrogating it and recording the location of the wave glider from the onboard GPS receiver.

The transponder was deployed off the south coast of Oahu using the R/V Klaus Wyrtki. The deployment location and water depth were recorded based on the ship's 


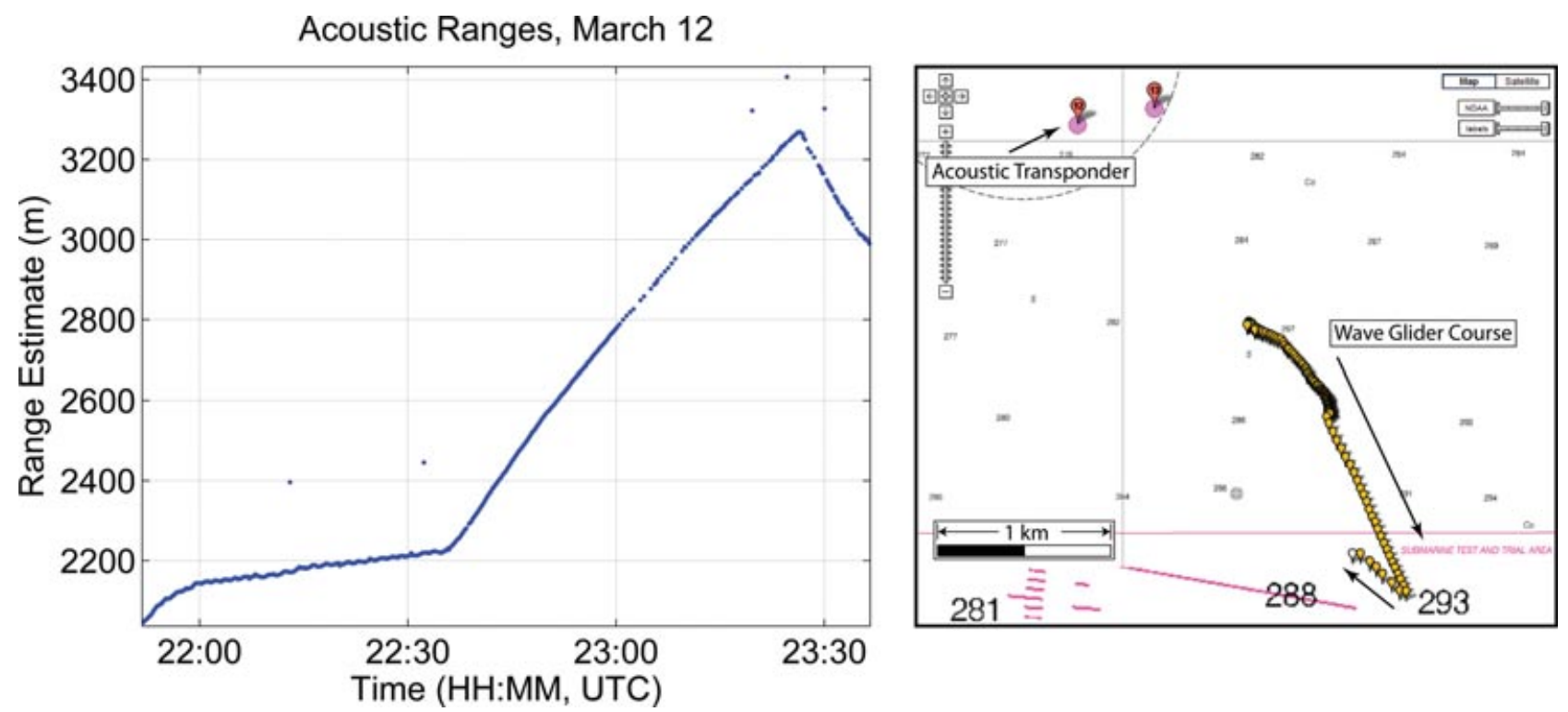

Figure 8. Results from acoustic range limit tests with UHM wave glider. (a) Unfiltered (raw) acoustic range measurements from transponder range test. Range estimates are produced from the reported one-way travel times and the approximate speed of sound in the area during operation. (b) Map illustrating the wave glider path during range estimates shown in (a).

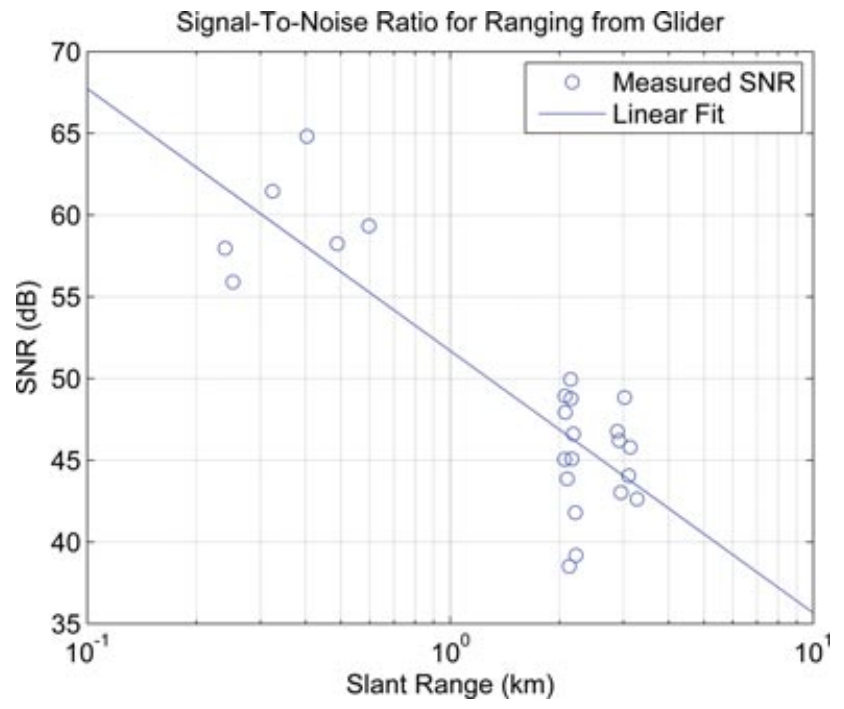

Figure 9. Graph of the SNR of the transponder receptions as a function of range from the transponder. Each SNR measurement (o) is estimated using the peak of the power level for each received transponder reply.

GPS receiver and fathometer. The wave glider was then commanded to transit a set of waypoints that would circle the drop location at a radius of approximately 1.4 times the transponder depth. This path can be shown to minimize the three-dimensional uncertainty of the resulting localization solution. The path and navigation waypoints are shown in Figure 7(b).

During the 2.5-h survey, over 971 range observations $\left(z_{r_{i}}\right)$ were made using the micro-modem; the measurements are indexed by $i$. Using the Trimble GPS receiver output and an estimate of the ITC-3013 transducer location relative to the GPS antenna, we determined the location of the transducer at each range observation $\left(\mathbf{X}_{\mathrm{gps}_{i}}=\right.$ $\left.\left(x_{\mathrm{gps}_{i}}, y_{\mathrm{gps}_{i}}, z_{\mathrm{gps}_{i}}\right)\right)$. We approximate the horizontal position of the transducer mounted on the submerged glider based on the horizontal position of the surface float. We are currently working on a dynamic model to provide an improved estimate of the actual glider location. Based on the unknown position of the subsea transponder $\left(\mathbf{X}_{t}=\right.$ $\left.\left(x_{t}, y_{t}, z_{t}\right)\right)$ and the observed transducer locations, we can predict the range observations as

$$
\begin{aligned}
\hat{z}_{r_{i}} & =\left\|\mathbf{X}_{\mathrm{gps}_{i}}-\mathbf{X}_{t}\right\| \\
& =\left[\left(x_{\mathrm{gps}_{i}}-x_{t}\right)^{2}+\left(y_{\mathrm{gps}_{i}}-y_{t}\right)^{2}+\left(z_{\mathrm{gps}_{i}}-z_{t}\right)^{2}\right]^{1 / 2} .
\end{aligned}
$$

To estimate the fixed transponder location, we minimize the root-mean-squared error between the observed and predicted range values:

$$
\hat{\mathbf{X}}_{t}=\min _{\mathbf{X}_{t} \in \mathbb{R}^{3}}\left(\sqrt{\sum_{i}^{N}\left(\hat{z}_{r_{i}}-z_{r_{i}}\right)^{2}}\right) .
$$

This straightforward minimization problem (1) can be solved with a variety of standard techniques. The resulting 
Table II. Results of transponder survey.

\begin{tabular}{lccc}
\hline & & & \\
& Latitude (N) & Longitude (W) & Depth (m) \\
\hline Surface deployment & $21^{\circ} 16.664^{\prime}$ & $157^{\circ} 55.057^{\prime}$ & 235.2 \\
Acoustic survey & $21^{\circ} 16.666^{\prime}$ & $157^{\circ} 55.066^{\prime}$ & 235.7 \\
Difference (m) & 3.71 & 15.54 & 0.5 \\
\hline
\end{tabular}

average root-mean-squared error was $1.72 \mathrm{~m}$, giving an indication of the precision of the localization. This result is within the range of previously published results based on ship-based surveys (Bingham et al., 2010; Whitcomb et al., 1998). The final solution made use of 955 range observations. Outliers were removed via an iterative random sample consensus (RANSAC) method (Fischler \& Bolles, 1981). (Only 16 outliers were rejected out of 971 measurements.) The time necessary to complete the survey is constrained by the speed of the wave glider, which is limited to approximately $0.75 \mathrm{~m} / \mathrm{s}$ (1.5 kts). Surveys using a surface ship are typically carried out at similar speeds to reduce flow noise and allow for sufficient coverage.

Table II summarizes the results of the transponder survey, comparing the acoustic survey results with the information from the deployment location. The deployment location was estimated based on the ship's GPS receiver and fathometer at the time of deployment. Generally this initial location is a coarse estimate, especially in deep water, because of the drift associated with descent and the accuracies of deep-water bathymetry. The values for depth account for the 6.1-m tether used to moor the transponder to the bottom and the depth of the wave glider transducer below the surface. The solution does not account for the horizontal offset of the glider-mounted transducer due to the angle of the umbilical. Our initial models predict that this angle oscillation would be less than $4.5^{\circ}$, which could introduce an uncertainty of as much as $0.55 \mathrm{~m}$ horizontally because of the 7-m-long umbilical. For this experiment, the proximity of the deployment location estimate to the acoustic survey result is due to the shallow water. This provided a coarse ground truth for the experiment. The difference between the transponder deployment location at the surface and the result of the acoustic survey is also conveyed in Table II. The total difference is $16.0 \mathrm{~m}$.

\section{RESULTS OF ACTIVE ACOUSTIC EXPERIMENTS: COMMUNICATION}

The acoustic communications experiments employed the micro-modem installed on the WHOI wave glider plus shipboard and seafloor moored acoustic modems. The transducer on the WHOI wave glider is installed in the surface float as illustrated in Figure 2(d). The shipboard modem was used for system checkout, and the moored modems for testing transmission of data from the seafloor to the surface. Several experiments were done, utilizing mooring at two different depths.

The moored modem was programmed to transmit at regular intervals and deployed with an acoustic release in both 500-m and 2,500-m water depths off Honolulu during the test period. The modem on the wave glider was also equipped with a controller that would initiate acoustic transmissions to the seafloor modem. Different data rates, bandwidths, and carrier frequencies were utilized during the test and the data were logged for subsequent analysis. The figure of merit that is used in estimating the reliability of the acoustic communications is the SNR at the input of the receiver, which was characterized during the experiment.

The initial findings, after review of data collected from both the micro-modem and the recorder, were that the wave glider modem was able to receive signals from the transmitter at depths of 500 and 2,500 $\mathrm{m}$ and at ranges in excess of $3 \mathrm{~km}$, but that the reliability and the input SNR varied with the local noise field around the surface receiver. An example spectrogram of a received acoustic packet at 10$\mathrm{kHz}$ carrier with $5-\mathrm{kHz}$ bandwidth is shown in Figure 10 The 4-s-long packet is clearly visible. More interesting is the noise that is present as well. Note that the spectrum is different from that recorded by the D-MON because the modem's bandpass filters remove most of the low-frequency signal prior to recording. Thus the characteristic sloshing noises easily identified on the D-MON recordings are not present here. Instead, the noise is higher-frequency and

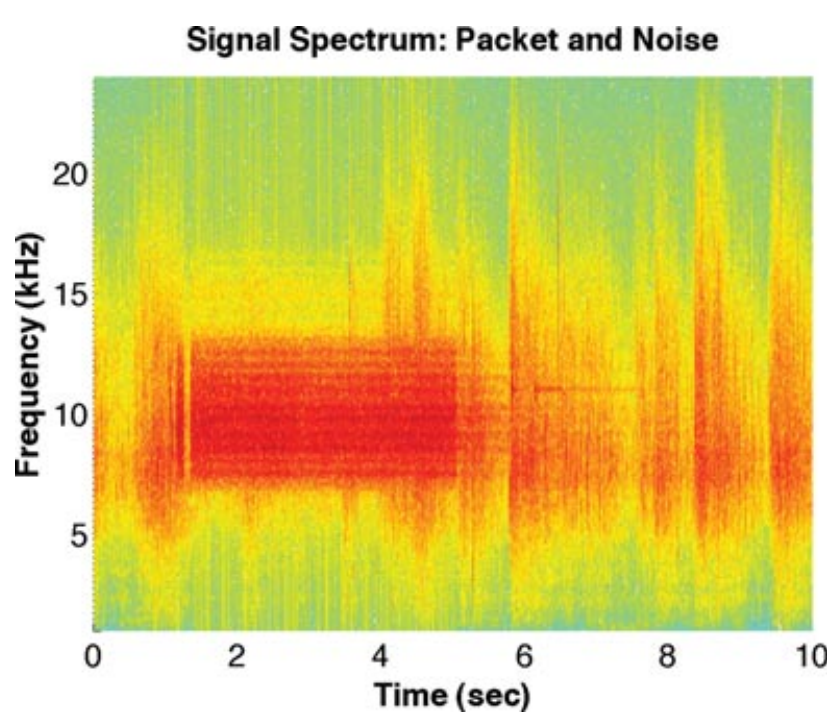

Figure 10. An acoustic communications packet as received on the transducer embedded in the surface float of the WHOI glider. The packet, visible between 1.5 and $5 \mathrm{~s}$, is centered at $10 \mathrm{kHz}$ and is clearly visible despite the surface-generated noise. 
likely results from a combination of frequency-dependent flow and structural noise, plus bubble fields that are present near the glider.

Despite the additional noise from this combination of sources, the acoustic modem often received error-free data, and the reliability was correlated with the intensity and duty cycle of the noise. As illustrated in Figure 10, the noise is often at the same level as the received signal, reducing the SNR at those points in time to $0 \mathrm{~dB}$. The time variability of the noise thus makes portions of the data stream unreliable, and the probability of the individual frames that make up a packet being successfully received depends on their position relative to the noise. However, because the source level is high $(185 \mathrm{~dB})$, when the glider was directly overhead, the input SNR was greater than $30 \mathrm{~dB}$, and the link was very reliable. Only occasionally would bad packets be received.

\section{DISCUSSION AND CONCLUSION}

Based on our modifications and testing of these two wave gliders, we can draw some important conclusions about the general capabilities of this new platform for passive and active acoustic applications. First, the acoustic survey of the self-noise shows that the platform radiates very little noise, making it an ideal platform for passive monitoring. The disparity between the spectra at the surface float and the submerged glider illustrates that there is considerable noise at the surface, even under calm ocean conditions. This suggests that for passive acoustic applications the receivers need to be placed well below the surface float. The marine mammal detections illustrate the efficacy of such a configuration. With the available satellite telemetry and the ability for persistent presence, this type of integrated solution could provide, for example, real-time monitoring of marine mammals for ship strike prevention.

The active acoustic evaluations show that the wave glider is a capable platform to act as an acoustic navigation and communication gateway for other submerged assets. The transponder localization survey evaluation illustrates the potential accuracy of such solutions as a result of the low radiated noise from the platform. Because of the high SNR of this type of active application, the results suggest that the location of the receiving transducer is less sensitive to location; i.e., the transponder replies were sufficiently strong to be received at either the lower glider or the upper float locations. The same is true for the acoustic communications; at close range there is sufficient SNR for the floatmounted transducer to operate well, but as range increases the signal excess is reduced and bad packets become more common.

Overall, the analysis of the field experiments described in this article quantify the performance of this novel platform for passive and active acoustic applications. The results suggest that the wave glider has the potential to be an important part of future passive and active acoustic appli- cations, but that the ambient noise near the vehicle needs to be considered in locating transducers on the vehicle.

\section{ACKNOWLEDGMENTS}

This work is sponsored by the Defense Advanced Research Projects Agency and the National Defense Center for Excellence for Research in Ocean Sciences. The content of the information does not necessarily reflect the position or the policy of the federal government or the state of Hawaii, and no official endorsement should be inferred.

We wish to thank Dr. Mark Johnson and Tom Hurst (WHOI) for graciously providing and supporting a D-MON beta test unit for evaluation, the captain and crew of the R/V Klaus Wyrtki for their support of these field experiments, and Dr. Eric Prechtl (Axis Engineering Technologies, Inc.) for his support of instrument integration.

Also, the processing framework for transponder localization was originated in the early 1990s at the Deep Submergence Lab, Woods Hole Oceanographic Institution by Dr. Dana Yoerger and Steve Gegg.

\section{REFERENCES}

Austin, T., Stokey, R., \& Sharp, K. (2000, September). PARADIGM: A buoy-based system for AUV navigation and tracking. In Proceedings of the MTS/IEEE OCEANS Conference, Providence, RI (vol. 2, pp. 935-938).

Baumgartner, M., \& Fratantoni, D. (2008). Diel periodicity in both sei whale vocalization rates and the vertical migration of their copepod prey observed from ocean gliders. Limnology and Oceanography, 53, 2197-2209.

Bingham, B., Foley, B., Singh, H., Camilli, R., Delaporta, K., Eustice, R., Mallios, A., Mindell, D., Roman, C., \& Sakellariou, D. (2010). Robotic tools for deep water archaeology: Surveying an ancient shipwreck with an autonomous underwater vehicle. Journal of Field Robotics, 27(6), 702-717.

Curcio, J., Leonard, J., Vaganay, J., Patrikalakis, A., Bahr, A., Battle, D., Schmidt, H., \& Grund, M. (2005, September). Experiments in moving baseline navigation using autonomous surface craft. In Proceedings of the MTS/IEEE OCEANS Conference, Washington, D.C. (pp. 730-735).

Desset, S., Damus, R., Morash, J., \& Bechaz, C. (2003). Use of GIBs in AUVs for underwater archaeology. Sea Technology, 44(12), 22-27.

Eustice, R., Whitcomb, L., Singh, H., \& Grund, M. (2007, April). Experimental results in synchronous-clock oneway-travel-time acoustic navigation for autonomous underwater vehicles. In 2007 IEEE International Conference on Robotics and Automation, Roma, Italy (pp. 4257-4264).

Fischler, M. A., \& Bolles, R. C. (1981). Random sample consensus: A paradigm for model fitting with applications to image analysis and automated cartography. Communications of the ACM, 24(6), 381-395.

Frankel, A. S., Clark, C. W., Herman, L. M., \& Gabriele, C. M. (1995). Spatial distribution, habitat utilization, and social interactions of humpback whales, Megaptera novaeangliae, off Hawai'i, determined using acoustic and 
visual techniques. Canadian Journal of Zoology, 73(6), 1134-1146.

Freitag, L., Grund, M., Singh, S., Partan, J., Koski, P., \& Ball, K. (2005). The WHOI micro-modem: An acoustic communications and navigation system for multiple platforms. In Proceedings of the MTS/IEEE OCEANS Conference (vol. 2, pp. 1086-1092).

Frye, D., Ware, J., Grund, M., Partan, J., Koski, P., Singh, S., Freitag, L., Collins, J., \& Detrick, R. (2005). An acousticallylinked deep-ocean observatory. In Proceedings of the IEEE OCEANS 2005-Europe Conference, Brest, France (vol. 2, pp. 969-974).

Fujita, M., Ishikawa, T., Mochizuki, M., Sato, M., Toyama, S., Katayama, M., Kawai, K., Matsumoto, Y., Yabuki, T., Asada, A., \& Colombo, O. L. (2006). GPS/acoustic seafloor geodetic observation: Method of data analysis and its application. Earth Planets Space, 58, 265-275.

Hine, R., Willcox, S., Hine, G., \& Richardson, T. (2009). The wave glider: A wave-powered autonomous marine vehicle. In Proceedings of MTS/IEEE OCEANS Conference (pp. 1-6).

Howe, B. M., \& Boyd, M. L. (2008). Using seagliders for acoustic receiving and communication. Journal Acoustical Society of America (Abstract), 123, 3913.

Howe, B. M., Mercer, J. A., \& Spindel, R. C. (1989). A floating acoustic-satellite (FAST) range. In Proceedings of the Conference on Marine Data Systems, New Orleans, Washington, D.C. (pp. 225-230). Marine Technology Society.

Hunt, M., Marquet, W., Moller, D., Peal, K., Smith, W., \& Spindel, R. (1974). An acoustic navigation system. (Tech. Rep. WHOI-74-6). Woods Hole Oceanographic Institution, Wood Hole, MA.

Kinsey, J. C., Eustice, R. M., \& Whitcomb, L. L. (2006). Underwater vehicle navigation: Recent advances and new challenges. Invited paper presented at the IFAC Conference on Manoeuvring and Control of Marine Craft, Lisbon, Portugal.

Klinck, H., Stelzer, R., Jafarmadar, K., \& Mellinger, D. (2009, July). AAS Endurance: An autonomous acoustic sailboat for marine mammal research. In Proceedings of International Robotic Sailing Conference, Matosinhos, Portugal (pp. 43-48).

Kussat, N. H., \& Chadwell, C. D. (2005). Absolute positioning of an autonomous underwater vehicle using GPS and acoustic measurements. IEEE Journal of Oceanic Engineering, 30(1), 153-164.

Lawson, R., Graham, D., Stalin, S., Meinig, C., Tagawa, D., Lawrence-Slavas, N., Hibbins, R., \& Ingham, B. (2011, September). The next generation easy-to-deploy (ETD) tsunami assessment buoy. In Proceedings of the MTS/IEEE OCEANS Conference, Kona, HI (pp. 1-8).

Leonard, J. J., Bennett, A. A., Smith, C. M., \& Feder, H. J. S. (1998). Autonomous underwater vehicle navigation (Tech. Rep. 98-1), Marine Robotics Laboratory, Cambridge, MA.

Meinig, C., Stalin, S. E., Nakamura, A. I., \& Milburn, H. B. (2005). Real-time deep-ocean tsunami measuring, monitoring, and reporting system: The NOAA DART II description and disclosure (Tech. Rep.). National Oceanic and Atmospheric Administration, Pacific Marine Environmental Laboratory, Seattle, WA.

Mellinger, D., \& Clark, C. (2006). MobySound: A reference archive for studying automatic recognition of marine mammal sounds. Applied Acoustics, 67(11-12), 12261242.

Mellinger, D. K., \& Barlow, J. (2003). Future directions for marine mammal acoustic surveys: Stock assessment and habitat use (Tech Contrib. 2557). NOAA Pacific Marine Envirnomental Laboratory, Seattle, WA.

Mellinger, D. K., Stafford, K. M., Moore, S. E., Dziak, R. P. \& Matsumoto, H. (2007). An overview of fixed passive acoustic observation methods for cetaceans. Oceanography, 20(4), 36-45.

Milne, P. H. (1983). Underwater acoustic positioning systems. Houston: Gulf Publishing Company.

Moore, S. E., Howe, B. M., Stafford, K. M., \& Boyd, M. L. (2008). Including whale call detection in standard ocean measurements: Applications of acoustic seagliders. Marine Technology Society (MTS) Journal, 41, 53-57.

Obana, K., Katao, H., \& Ando, M. (2000). Seafloor positioning system with GPS-acoustic link for crustal dynamics observation: A preliminary result from experiments in the sea. Earth Planets Space, 52, 415-423.

Osada, Y., Fujimoto, H., Miura, S., Sweeney, A., Kanazawa, T., Nakao, S., Sakai, S., Hildebrand, J., \& Chadwell, C. (2003). Estimation and correction for the effect of sound velocity variation on GPS/acoustic seafloor positioning: An experiment off Hawaii Island. Earth Planets Space, 55, e17-e20.

Spiess, F. N., Boegeman, D. E., Zimmerman, R., Chadwell, C. D., \& Hildebrand, J. A. (1997). Precision transponder (Tech. Rep. SIO Ref. 97-3). University of California, San Diego, Scripps Institition of Oceanography, La Jolla CA.

Spiess, F. N., Chadwell, C. D., Hildebrand, J. A., Young, L. E., Purcell, G. H. Jr., and Dragert, H. (1998). Precise GPS/acoustic positioning of seafloor reference points for tectonic studies. Physics of Earth Planetery Interiors, 108(1), 102-112.

Stutters, L., Liu, H., Tiltman, C., \& Brown, D. (2008). Navigation technologies for autonomous underwater vehicles. IEEE Transactions on Systems, Man, and Cybernetics, Part C: Applications and Reviews, 38(4), 581-589.

Sweeney, A. D., Chadwell, C. D., Hildebrand, J. A., \& Spiess, F. N. (2005). Centimeter-level positioning of seafloor acoustic transponders from a deeply-towed interrogator Marine Geodesy, 28(1), 39-70.

Vaganay, J., Leonard, J., Curcio, J., \& Willcox, J. (2004). Experimental validation of the moving long base-line navigation concept. In Proceedings of the IEEE/OES Conference on Autonomous Underwater Vehicles (pp. 59-65).

Vestgard, K., Storkersen, N., \& Sortland, J. (1999). Seabed surveying with Hugin AUV. In Proceedings of the 11th International Symposium on Unmanned Untethered Submersible Technology.

Webster, S., Eustice, R., Singh, H., \& Whitcomb, L. (2009, October). Preliminary deep water results in single-beacon one-way-travel-time acoustic navigation for underwater 
vehicles. In IEEE/RSJ International Conference on Intelligent Robots and Systems, 2009. (IROS 2009), St. Louis, MO (pp. 2053-2060).

Whitcomb, L., Yoerger, D., Singh, H., \& Mindell, D. (1998). Towards precision robotic maneuvering, survey, and manipulation in unstructured undersea environments. In Y. Shirai, \& S. Hirose (Eds.), Robotics research-The Eighth International Symposium (pp. 45-54). London: SpringerVerlag.

Wiggins, S., Manley, J., Brager, E., \& Woolhiser, B. (2010, September). Monitoring marine mammal acoustics using wave glider. In Proceedings of the MTS/IEEE OCEANS Conference, Seattle, WA (pp. 1-4).

Wiggins, S. M., \& Hildebrand, J. A. (2007, April). Highfrequency acoustic recording package (HARP) for broad-band, long-term marine mammal monitoring. In Symposium on Underwater Technology and Workshop on Scientific Use of Submarine Cables and Related Technologies, Tokyo, Japan (pp. 551-557).

Willcox, S., Meinig, C., Sabine, C., Lawrence-Slavas, N., Richardson, T., Hine, R., \& Manley, J. (2009). An autonomous mobile platform for underway surface carbon measurements in open-ocean and coastal waters. In Proceedings of the MTS/IEEE OCEANS Conference (pp. 1-8).

Yamada, T., Ando, M., Tadokoro, K., Sato, K., Okuda, T., \& Oike, K. (2002). Error evaluation in acoustic positioning of a single transponder for seafloor crustal deformation measurements. Earth Planets Space, 54, 871881.

Yoerger, D. R., Jakuba, M., Bradley, A. M., \& Bingham, B. (2007). Techniques for deep sea near bottom survey using an autonomous underwater vehicle. International Journal of Robotics Research, 26(1), 41-54. 